\title{
SOCIEDADE E ESCOLA: ASPECTOS DA VISÃO DE ANÍSIO TEIXEIRA
}

\section{SCHOOL AND SOCIETY: ASPECTS OF VISION TEIXEIRA}

Daniel Estevão de Miranda (PG-UFScar/DCH/UFMS)

André Luiz da Motta Silva (PPGEduc/CCHS /UFMS)

\begin{abstract}
Resumo: $O$ artigo pretende apresentar os aspectos que constituem a visão de Anísio Teixeira em relação ao papel da escola, mais especificamente da escola pública, frente à família e à sociedade brasileira de seu tempo. Procurar-se-á expor a interpretação anisiana do papel social da escola na sociedade moderna, isto é, o modo como a "escola para todos", a máquina da democracia, assume o posto de principal instituição socializadora e estabilizadora, como elemento de superação do limitado modelo de socialização familiar e de classe, da nova ordem social configurada em torno da sociedade capitalista.
\end{abstract}

Palavras-chave: Anísio Teixeira. Escola e sociedade. Escola pública.

Abstract: This article aims to present the aspects that constitute the vision of Teixeira regarding the role of schools, specifically public school, in front of family and the Brazilian society of his time. Search will expose the Anisian interpretation of the social role of schools in modern society, ie how the "school for all, the machinery of democracy, assumed the post of chief socializing and stabilizing institution as part of overcoming the limited model of family socialization and class, the new social order set up around the capitalist society.

Key words: Anísio Teixeira. School and Society. Public School.

Em meio ao movimento histórico dos anos 1930-1960, uma sociedade que se pretendia efetivamente moderna e democrática não poderia deixar de lado os princípios norteadores da vida do novo tipo de homem que se exigia. Sendo assim, a escola teria de acompanhar, tal como o sistema político, os novos valores que as estruturas econômicas e sociais emergentes imprimiram sobre a ordem do conjunto das relações e das instituições sociais.

O novo universo ideológico, emergente na sociedade brasileira, faz com que as propostas educacionais de Teixeira assumam uma postura determinada em relação a uma configuração social em que as inovações em todos os campos exigiam um melhor e mais intenso processo de reestruturação da função do sistema de ensino frente a um mundo em constante transformação. Surge daí, a necessidade do planejamento de políticas públicas que visem regularizar e redistribuir os avanços da nova realidade, na qual a sociedade moderna deve ser, ao mesmo tempo, estável e dinâmica. Uma sociedade estabilizada é uma sociedade onde há harmonia entre dinamicidade e ordem. Uma sociedade democrática deve 
prezar pela estabilidade de suas instituições e, ao mesmo tempo, apreciar as inovações que contribuem para sua manutenção.

Anísio Teixeira, seguindo a tradição do pragmatismo estadunidense, sob a influência de John Dewey e William Kilpatrick ${ }^{1}$, era defensor de reformas que viessem democratizar as oportunidades educacionais e reconhecer a importância da experiência do senso comum na construção da inteligência. A escola pública e democrática surge na interpretação social anisiana como a única capaz de instituir, na ordem social capitalista, mecanismos de aperfeiçoamento do sistema democrático e de correção dos desvios e males causados pela exacerbação da industrialização e do individualismo. Esta escola, aberta a todas as classes e camadas sociais, deveria ser o produto da reorganização e reconstrução da escola existente, da racionalização e profissionalização do processo educativo, tornandoa apta a assumir sua função social de "máquina" preparadora da sociedade democrática e produtora do "homem novo".

A visão de Anísio Teixeira, um liberalismo igualitarista, voltava-se para a democratização das oportunidades educacionais como a forma mais justa de equalização social. Uma escola aberta a todas as classes sociais, no pensamento anisiano, é a edificadora dos alicerces de uma sociedade aberta e democrática na qual a ascensão social deve ocorrer não pelos privilégios de classe, mas de acordo com um regime meritocrático onde a estratificação social se dá em concordância com as capacidades individuais.

Anísio Teixeira procura demonstrar que, numa sociedade antidemocrática, a educação se constitui como um privilégio de falsas "elites" que detém um poder econômico, mas na sociedade que se reconstrói, em marcha para a ordem social democrática, a educação se apresenta como um direito que deve ser garantido para todos pelo Estado, como forma de dar ao movimento de ascensão e organização da sociedade democrática os rumos e a legitimidade necessários ao processo de estabilização social.

Assim, o liberalismo anisiano é igualitário, e não elitista, pois sua preocupação primordial é a de possibilitar iguais oportunidades educacionais para todos, para que qualquer indivíduo possa participar ativa e criticamente das mudanças que a sociedade baseada na ciência e na técnica possibilita. Essa seria a principal função social atribuída por Anísio Teixeira à escola no Brasil dos anos 1930-1960, sendo a formação de "elites" científicas, técnicas e dirigentes apenas consequências secundárias deste processo e não seu principal objetivo. Dessa forma, para se entender o papel que a escola progressiva ou para todos assume no pensamento político-pedagógico anisiano, é preciso, primeiramente, compreender a escola e a sociedade por ele ansiadas.

A escola adquire nas reflexões filosóficas elaboradas por Anísio Teixeira, uma posição fundamental. O pensamento anisiano aponta a necessidade de se construir um sistema educacional. Nesse sentido, a perspectiva anisiana tem na escola e na educação não só os elementos para a perpetuação dos valores sociais, mas, instrumentos importantíssimos para assegurar, também, um interminável processo de reconstrução social. Anísio Teixeira (2000, p.189) reconhece que:

\footnotetext{
1 As duas principais obras desses autores, em que influenciaram profundamente Anísio Teixeira, são: DEWEY, John. Democracia e educação. São Paulo: Companhia Editora Nacional, 1959. KILPATRICK, William. A Educação para uma sociedade em mudança. Rio de Janeiro: Melhoramentos, 1972.
} 


\begin{abstract}
A educação de um povo somente em parte se faz pelas suas escolas. Compreendida como o processo de transmissão da cultura, ela se opera pela vida mesma das populações e, mais especificamente, pela família, pela classe social e pela religião. A escola, como instituição voluntária e intencional, acrescenta-se a essas outras instituições fundamentais de transmissão da cultura, como um reforço, para completar, harmonizar e tornar mais consciente a cultura, em processo natural de transmissão, e, nas sociedades modernas de hoje, para habilitar o jovem à vida cívica e de trabalho, em uma comunidade altamente complexa e de meios de vida crescentemente especializados.
\end{abstract}

Anísio Teixeira (1956, p.9) procurou desenvolver o tema da função social da escola frente às outras instituições sociais, em especial a classe social e a família, fixando como parâmetro para suas interpretações e propostas a conexão incontestável entre educação e democracia. O "postulado fundamental" do pensamento político-educaional anisiano estava baseado na ideia de que por meio da escola pública e democrática seria possível, uma vez que todos os homens são "suficientemente educáveis", fazer com que todos os indivíduos fossem capazes de "partilharem como iguais" as possibilidades que a vida em sociedade pode fornecer. Nesse sentido, "a escola democrática ou para todos", marca indelével da obra educacional de Anísio Teixeira, seria movida por valores e finalidades que transcenderiam os muros da escola, sendo estas, exigências do modo de vida democrático. Para realizar sua função social, a escola para todos deveria oferecer uma "educação comum" para a totalidade dos membros da sociedade, pois se antes a educação era oferecida espontaneamente por meio da família, da classe e do contato com a vida social, com o avanço da sociedade urbano-industrial a educação se faz cada vez mais uma obrigação da sociedade e do Estado enquanto instituições educadoras.

Para Anísio Teixeira, a instituição familiar, em meados do século $\mathrm{XX}$, já não detinha todos os meios capazes de prover os preceitos basilares e necessários aos indivíduos para se sustentarem e acessarem os valores tidos como válidos pela lógica social em consolidação, isto é, a uma sociedade marcadamente mais urbana e industrial. $\mathrm{O}$ alto grau de complexificação das relações socais e da vida moderna como um todo, transformações materiais e imateriais, não permitia a família e a classe social continuarem como "instituições seguras e incontrastáveis" como haviam sido anteriormente. Ao mesmo tempo, Teixeira procurava ressaltar que mesmo que ambas, família e classe, mantivessem asseguradas suas atribuições morais, ainda assim, a escola se manteria como mais que fundamental, pois estas instituições não poderiam cumprir com a tarefa que só à escola democrática cabia. A ela, a "escola comum e democrática", compete zelar pela constituição de um ambiente adequado que propicie ao educando novas experiências que permitam, ao mesmo tempo, a revisão e a integração à experiência da vida em comunidade. Assim, o educando assumiria o seu papel, como assevera Anísio Teixeira (1956, p. 9), de

[...] participante inteligente e ajustado de uma sociedade de todos e para todos, em que o respeito e o interesse pelos outros se estendam além das estratificações sociais e de grupo e se impregnem do espírito de que, antes de membro da 


\section{INTERFACES DA EDUCAÇÃO}

família, do grupo ou da classe, o indivíduo é membro de sua comunidade, do seu país e de toda a humanidade.

Dessa forma, a formação dos indivíduos, na sociedade que caminha para a democracia, deve prezar pelos padrões de socialização e sociabilidade requeridos pela ordem social democrática. Para a constituição da cidadania democrática, ao contrário de uma educação baseada em valores orientados para o contentamento de interesses individual-particulares e locais, como o faziam a família, a classe ou o grupo, a organização moderna e tendencialmente democrática da sociedade requer homens capazes de reconhecer claramente seus direitos e deveres, portadores de uma visão ampliada de seus papéis para com a comunidade mais próxima, mas também, para com seu país e com a sociedade humana como um todo.

A escola proposta por Anísio Teixeira só pode ser entendida e considerada como o instrumento que dá ao processo educativo, que tem sua origem nas instituições sociais fundamentais, os rumos necessários para que o indivíduo/educando seja capaz de integrar a sociedade de modo a contribuir para a marcha da civilização moderna. Por ter o compromisso de zelar pelos valores sociais, Anísio destaca que a escola progressiva (a nova escola) deve deixar de ser um elemento isolado das transformações sociais, como o faz a escola tradicional, mas fazer-se, cada vez mais, uma micro-projeção da realidade social, para que se torne eficiente e apta a acompanhar os ritmos acelerados de aperfeiçoamento da ciência, da técnica, e das relações sociais como um todo. Quanto a isso Anísio Teixeira (2000, p. 110-111) afirma que:

\footnotetext{
Vai, porém, muito adiantada a marcha da humanidade, nas suas adaptações e readaptações sucessivas. A natureza se fez arte e, hoje, viver é um difícil mister, que é preciso aprender. Mais do que isso. As mudanças são tão aceleradas que, se a distância e a diferença de ritmo entre a escola e a sociedade permanecessem as mesmas de outros tempos, ao terminarmos a nossa educação escolar, seria necessário começá-la de novo, tão longe, tão adiante já se acharia a vida... Por tudo isso, a escola teve que deixar de ser a instituição isolada, tranqüila, do outro mundo, que era, para se impregnar do ritmo ambiente e assumir a consciência de suas funções. Se depressa marcha a vida, mais depressa há de marchar a escola. Dentro da transformação real que se vai operando na escola, ainda não há, entretanto, as mais das vezes, senão a consciência de que os seus deveres antigos - de guarda e perpetuadora dos valores sociais - só poderão ser cumpridos criando-se dentro da escola um ambiente idêntico ao da sociedade, onde se possam preparar as crianças para a participação em uma civilização técnica e dinâmica.
}

O homem da civilização em mudança vive uma realidade onde a materialidade do meio é, em grande parte, fruto da educação, sendo assim, ela é o principal pilar sustentador de toda a vida social. Ao apontar esta função da educação, Anísio procura chamar a atenção para o fato de que a escola do mundo moderno não pode ser a antiga escola "acidental, sem planos e sem previsão" (TEIXEIRA, 2000, p.111). O antigo mundo do fatalismo foi superado pelo novo universo da "civilização industrial e experimental" (p.112). A compreensão das novas possibilidades que a ciência trouxe para a humanidade implica uma completa revisão da função social da escola. As escolas não podem mais ser "casas 
pacíficas de cultura literária e artística, destinadas a atuar na formação de um corpo de fiéis às tradições do estudo e do saber" (TEIXEIRA, 2000, p. 112), surge então, a obrigação de formar um novo homem para uma nova sociedade industrial, técnica e em plena mutação.

A ciência ganha grande destaque no pensamento anisiano, mas ele compreende que durante um tempo houve "um entusiasmo exagerado e complacente" (p. 112) em relação aos usos da ciência. Esse ardor científico de conquista do futuro teve como consequência a elevação das injustiças sociais. Para reverter esta situação, só um novo modelo de escola poderia contribuir para a superação das iniquidades sociais. Como ressalta Anísio (p. 113),

Apenas, - e agora é que se acentua a transformação fundamental por que passa a escola - apenas, urge que não entreguemos ao acidente e ao acaso o que podemos prever e planejar. A escola não pode ficar no seu estagnado destino de perpetuadora da vida social presente. Precisa transformar-se no instrumento consciente, inteligente do aperfeiçoamento social. Não nos é dado dizer de antemão o que poderá representar de correções, de ajustamentos e de regularização do processo social, o aproveitamento inteligente dela escola para esse fim, seu verdadeiro fim. A grande tarefa dos nossos dias é preparar o homem novo para o mundo novo, que a máquina e a ciência estão exigindo. Até agora, temos um homem ainda antigo, excedido e subjugado pela sua própria criação. A máquina, que o vem libertar, o está escravizando. O industrialismo, que lhe vem dar conforto e força, o está fazendo morrer à fome. A liberdade de julgamento pessoal e de auto-direção o está asfixiando, transmudada em trágico tumulto de idéias e propósitos ${ }^{2}$.

Como se pode observar neste trecho, novamente a urgência em preparar o indivíduo moderno reaparece no discurso anisiano. As injustiças sociais aparecem mais como resultado do despreparo dos homens em lidar com as transformações, incapacidade de fazer das mudanças, chaves para o progresso social, do que consequências das determinações históricas. Esse desequilíbrio entre sociedade e educação deveria ser equacionado por meio da escola. Desse modo, a escola não pode ficar alheia ao processo de mudança e até de desagregação das instituições transmissoras da cultura (família, classe e religião), o que não é apenas resultado das constantes mudanças, mas, em especial, fruto das mudanças internas que estas instituições são obrigadas a realizar para acompanharem o novo ritmo da vida social.

Compreendendo estas imposições que a nova configuração social (capitalismo monopolista) projetava, em escala global, sobre os ideais de constituição de uma sociedade efetivamente democrática, Anísio Teixeira procura adaptar o modelo de escola progressiva, elaborado por Dewey, ao conjunto da realidade social brasileira. É pensando a escola inserida na diversidade geográfica e sociocultural brasileira, que o conceito de "escola progressiva" vai cedendo lugar a idéia de "escola para todos".

Para a concretização de uma sociedade democrática no Brasil, Anísio evidencia a inevitável superação das desigualdades herdadas durante mais de três séculos de transplantação cultural e institucional oriundas do período colonial e amplamente

\footnotetext{
${ }^{2}$ Grifos do autor.
} 
disseminada pela consciência coletiva. A herança colonial impôs sobre a sociedade brasileira uma estrutura social, mesmo depois de sua independência política, e por um bom período após a proclamação da república, inúmeras características que não mais correspondiam às transformações que ocorriam em diversos campos da vida social (nas ciências, nas técnicas, nas artes etc.). Anísio assevera que tudo o que havia de mais atrasado foi herdado pelo tipo de colonialismo exercido por Portugal. Enquanto outras nações européias, entre elas a Inglaterra, desenvolviam uma ação colonizadora que tinha como propósito estabelecer comunidades e incentivar-lhes certa autonomia, Portugal exercia uma relação puramente parasitária, pois só se movimenta de acordo com suas exigências imediatas, preferindo apenas saquear suas colônias e sujeitá-las aos seus mandos e desmandos. Ele destaca, também, que ao mesmo tempo em que a Inglaterra representava o ímpeto avassalador da Reforma Protestante frente às arcaicas estruturas sociais, resquícios da mentalidade medieval que ainda se apresentavam na organização social e política européia, Portugal transplantava para as terras brasileiras o que havia de mais extemporâneo, todo um modelo de estratificação social baseado nos princípios da Contrareforma, pois esta era justificadora das desigualdades e legitimadora de seu modelo exploratório de colonização. Deste processo histórico, formou-se uma visão da realidade pautada em dualismos sendo que, entre eles, o principal seria o estabelecido entre "elite" e "povo" 3 .

O legado deixado pela transplantação cultural/institucional, no que tange à educação, foi uma escola, no todo, voltada para atender às necessidades de ensino de uma elite, ou seja, uma educação para o lazer e o consumo. Uma escola totalmente aquém da população como um todo, uma escola a serviço da manutenção dos privilégios das classes detentoras do poder econômico e, consequentemente, do político. Quanto a esse aspecto, Anísio Teixeira chama a atenção para o fato de que: "A elite dinástica, visando, acima de tudo, preservar a tradição, oferece uma educação, apenas, aos poucos e, especialmente, a grupos seletos e destinados a constituir a elite governante." (TEIXEIRA, 1977a, p. 197). Ao firmar-se sobre esta base, a escola deixa, como pensa Teixeira, de cumprir com seu papel elementar na civilização industrial, isto é, ao ser domínio dos interesses de uma dada classe, ela não contribui para o aperfeiçoamento social.

Procurando romper com a escola tradicional (elitista e livresca, humanista, mas distanciada da vida real dos homens), Anísio Teixeira irá enfatizar em seus escritos a importância da socialização de uma escola pública, laica e em consonância direta com a realidade social e suas transformações nos mais variados campos (das artes, esportes, ciência, técnica, cultura etc.). Mas, além disso, a escola pública deveria ser a viga mestra de uma sociedade democrática, pois nela, o espírito da solidariedade democrática seria

\footnotetext{
${ }^{3}$ Para uma exposição mais pormenorizada das análises anisianas sobre as heranças culturais e o sobre o dualismo na organização da vida social brasileira, cf. BARREIRA. Luiz Carlos. Escola e formação da mentalidade do desenvolvimento no discurso político pedagógico de Anísio Teixeira. In: MONARCHA, Carlos (org.). Anísio Teixeira: a obra de uma vida. Rio de Janeiro: DP\&A, 2001, p.103-112; FREITAS, Marcos Cezar de. História, antropologia e pesquisa educacional: itinerários intelectuais. São Paulo: Cortez, 2001, p. 58-70.
} 
internalizado no educando e, mediante esse processo, a sociedade estaria contendo o avanço do egoísmo (resultado da deturpação do individualismo), crescente na sociedade moderna.

A escola pública é defendida nas reflexões anisianas como espaço no qual a aproximação social indiscriminada entre as múltiplas camadas que compõem a sociedade brasileira, construiria os vínculos de solidariedade e responsabilidade social e dissiparia qualquer forma de prevenção ou discriminação. Ela deve ser uma réplica da sociedade almejada, pois se vai servir a uma sociedade democrática, ela deve, antes de tudo, ser democrática. Nesse espaço, as crianças das classes populares encontrariam todo um ambiente próximo ao que as crianças privilegiadas têm em seus lares. Desse modo, a escola primária rompe com seu "ensino a toque de caixa", pois, tendo em vista que Teixeira defendia um ensino integral (realizado em escolas parque e escolas classe) ${ }^{4}$, ela teria tempo para ensinar mais do que apenas ler, escrever e contar. $\mathrm{O}$ espaço escolar se transformaria em uma extensão do ambiente familiar, permitindo desenvolver nas "crianças do povo" todos aqueles elementos necessários para uma vida melhor, para uma vida civilizada.

Um das grandes contradições do pensamento anisiano repousa, justamente, sobre esse papel da escola pública de oferecer aos desprivilegiados as vantagens presentes na vida familiar dos filhos da classe dominante e dos intelectuais. Anísio Teixeira é capaz de perceber essa diferença, mas ao mesmo tempo, ele acaba atribuindo-as, apenas, às disparidades de acesso aos elementos "civilizadores". Ao atribuir a eliminação das desigualdades a uma reforma do aparelho escolar, Teixeira demonstra não poder, devido às influências das limitações do método pluralístico deweyano (que muito abrange, mas pouco compreende em essência), captar as reais causas dessas desigualdades. O simples fato de em nenhum momento questionar a existência de diferenças de classe já demonstra sua visão parcial da realidade, não só brasileira, mas também, mundial.

Voltando à questão da democratização da escola, Anísio buscava uma escola comum, mas parece que este modelo só dizia respeito à escola primária. Quando Teixeira pensa a escola secundária, as coisas mudam, a formação primária (comum), responsável pela real aproximação social, dá lugar a uma escola secundária flexível, apta a atender uma clientela com múltiplas potencialidades e interesses (resultados da formação da personalidade no ambiente extra-escolar). Essa necessidade de flexibilização recai sobre um fato interessante. Essa escola flexível não parece mais manter vínculos com a escola comum, destinada ao ensino primário. Mesmo assim, ela é justificada por Anísio como garantia do respeito às diferenças individuais. Por isso, esse novo modelo de escola secundária deve procurar diversificar seus cursos, estabelecer uma articulação entre os estágios do sistema de ensino (ensinos: primário, secundário e superior), de modo que possa, por um lado, atender aos anseios democráticos de elevar ao máximo a disponibilidade de oportunidades educacionais aos cidadãos brasileiros e, também, fazer com que as diferenças de classe se dissolvam num ambiente, onde os indivíduos terão o mesmo valor/prestígio social, incondicionalmente. Quanto a esse descompasso, que parece existir entre uma escola comum e uma escola secundária flexível, Gandini (1980, p. 64) relata que:

\footnotetext{
${ }^{4}$ Cf. TEIXEIRA, 1977b, passim.
} 


\begin{abstract}
A diversificação dos cursos, a expansão das escolas secundárias, a articulação com o ensino primário, como forma de democratização da educação, seriam alguns dos caminhos para se eliminar a dualidade entre ensino acadêmico e o ensino profissional. Entretanto, essa mesma dualidade seria eliminada, através da unidade de objetivos, mas não através da uniformidade das escolas. Uma vez que continuariam os diferentes tipos de escola para formar pessoas com diferentes tipos de "aptidões" e capacidades, o que se poderia concluir é que seria eliminada a dualidade pela pluralidade e não pela escola comum, ou única, como o Autor declarava. Ou então seria esse o verdadeiro sentido da escola comum: compor-se de várias escolas diferentes entre si. Seria mantido, nessa diversidade, o fato de alguns chegarem à universidade e outros não ${ }^{5}$.
\end{abstract}

A idéia de uma escola classificadora (escola tradicional), extremamente criticada por Anísio Teixeira, é substituída por uma escola distribuidora, pois, ao levar em conta as potencialidades individuais e não os determinantes históricos (socioeconômicos, políticos e culturais), ela distribui o educando, a partir de suas "aptidões", pelas diversas profissões e, de acordo com a realidade da divisão social do trabalho. É por meio dessa escola distribuidora e científica que os mais aptos ao ensino superior, mesmo os que pertencem à massa pobre, conseguirão alcançar seus objetivos. A pluralidade de escolas, além de possibilitar um maior acesso a um grande número de cursos, justifica um ensino diferenciado, não mais pelas diferenças de classe (escolas e educação para os privilegiados/elites e ignorância para os desprivilegiados/massas), mas, por dissimilitudes de "aptidões" ("potencialidades", "habilidades", "disposições inatas", etc.). Desse modo, não parece ser uma simples questão terminológica a conversão da escola comum em uma escola para todos. A respeito disso, Gandini (p. 64-65) afirma que:

\begin{abstract}
A tarefa de destacar os pontos centrais das idéias de Anísio Teixeira, [...] é complexa, dada a dispersão e diversidade dos diferentes aspectos por ele abordados. Dessa forma, é preciso distinguir aquilo que ele (e outros liberais) entende por escola comum e o que entende por escola para todos. Essa separação é importante na medida em que o emprego de um e outro será a forma que o Autor encontra para realizar o que pretende fundamentalmente: a democratização da escola. A esse ideal corresponderia a escola comum. Entretanto, dada a diversidade da população, dada a diversidade entre as regiões brasileiras, a inviabilidade da proposta surge para ele, mas não querendo negá-la, contorna-a propondo a escola para todos, que não significa necessariamente escola comum.
\end{abstract}

A escola comum converte-se em escola para todos como forma de, mesmo com as limitações imposta pela formação social brasileira (onde a ciência era incipiente e o mundo rural ainda predominante), manter firme o ideal de democratização da escola. Anísio Teixeira é convicto em sua defesa, pois, para ele é só mediante a democratização da escola, da educação, das possibilidades, de uma nova mentalidade (democrática e pautada nas contribuições dos conhecimentos científicos), com uma reforma intelectual e moral, que será possível fazer da democracia formal uma democracia real, apesar dos pesares.

\footnotetext{
${ }^{5}$ Grifos da autora.
} 
Todas as observações feitas por Anísio Teixeira quanto à inviabilidade da manutenção do arcaico sistema de ensino, firmado na dualidade da oposição entre sistema de elite e sistema de massa, e da necessidade de uma legítima democratização das oportunidades educacionais, têm como objetivo a garantia de uma escola pública cuja função social primordial seja a de formação de indivíduos aptos a virem e se adequar às mudanças socioeconômicas (técnicas e cientificas) de uma sociedade em constante processo de reconstrução, ou seja, esta escola e sua educação democrática devem ser capazes de educar a população, em especial a classe trabalhadora, para que corresponda às exigências da nova configuração assumida pelo mundo da divisão social do trabalho, sob o controle da nova civilização urbano-industrial. A escola pública, principal "invenção" da sociedade moderna, deve ser a "máquina" mais importante da nova ordem econômicosocial, pois ela é a instituição fundamental da sociedade capitalista na medida em que se converte em elemento indispensável na disseminação do consenso requerido para a "produção" de indivíduos conformados com as condições sociais de existência por ela determinadas. Por isso, a produtividade e a eficiência no cumprimento da função social da escola são amplamente exaltadas, como características elementares do novo sistema educacional a ser firmado no interior da sociedade brasileira.

A escola pública é a "máquina que prepara as democracias" (TEIXEIRA, 1997, p. 230), porque é por meio dela e das demais instituições sociais, que a classe que exerce a hegemonia sobre o conjunto das relações sociais, pode fazer seus interesses intrínsecos atingirem e se espalharem pelo senso comum e, assim, assegurar a estabilidade/coesão social necessária para impedir qualquer tipo de manifestação (instabilidade/anomia ou desagregação social) que venha pôr em risco o modelo de estratificação social "aberto" da nova sociedade planificada/racionalizada e democrática. $\mathrm{O}$ espaço democrático, por excelência, passa a ser a escola pública (em especial a escola primária/básica ou escola para todos), pois nela, de acordo com o ideal anisiano, há um processo de socialização dos indivíduos acima das diferenças de classe ${ }^{6}$ e em total conexão com os avanços técnicos e científicos da nova fase de desenvolvimento e progresso social. Essa visão da escola, elaborada por Teixeira, não é capaz de visualizar o fato de que, ao servir de instrumento de legitimação das hierarquias sociais, esta instituição social contribui para a consolidação de todo um modelo de estratificação social que, embora ideologicamente justificável e tido como sinônimo de justiça social, ao fazer valer o princípio liberal meritocrático, é contraditória e concretamente injusta, ou melhor, as reais interconexões entre o sistema de ensino e o sistema de pensamento dominante, acabam escamoteadas.

Em suma, a escola pública tem como função social, para o pensamento social e político-pedagógico anisiano, garantir os pilares de sustentação da estabilidade social necessária à consolidação da nova ordem. O contato com a produção intelectual de Anísio Teixeira possibilita a percepção de que sua visão e defesa da mudança social só é viável desde que esteja em conformidade com a ordem vigente. Essa mudança não tem como resultado a superação da sociedade de classes, ao invés, ela se restringe a uma alternativa

\footnotetext{
${ }^{6}$ Esta crença na superação dos determinantes histórico-sociais e da sociedade de classes, da luta de classes, pura e simplesmente com a consolidação de um espaço democrático é uma das graves deficiências ou limitações do pensamento anisiano e deweyano.
} 
de readaptação do modelo de diferenciação social já existente e consolidado, às novas exigências do processo de "socialização da política" e organização da sociedade civil dentro das margens dadas pelo movimento de reorganização da sociedade capitalista, a partir da segunda metade do século XX.

\section{Referências}

GANDINI, Raquel Pereira Chainho. Tecnocracia, capitalismo e educação em Anísio Teixeira (1930-1935). Rio de Janeiro: Civilização Brasileira, 1980.

TEIXEIRA, Anísio. O processo democrático de educação. Revista Brasileira de Estudos Pedagógicos, Rio de Janeiro, v.25, n. 62, p. 3-16, abr./jun. 1956. $1977 \mathrm{a}$. . Educação e o mundo moderno. 2. ed. São Paulo: Companhia Editora Nacional, . Educação não é privilégio. 4. ed. São Paulo: Companhia Editora Nacional, 1977b.

. Educação para a democracia: introdução à administração educacional. Rio de Janeiro: Editora UFRJ, 1997.

Pequena introdução à filosofia da educação, ou, a transformação da escola. 6. ed. Rio de Janeiro: DP\&A, 2000. 